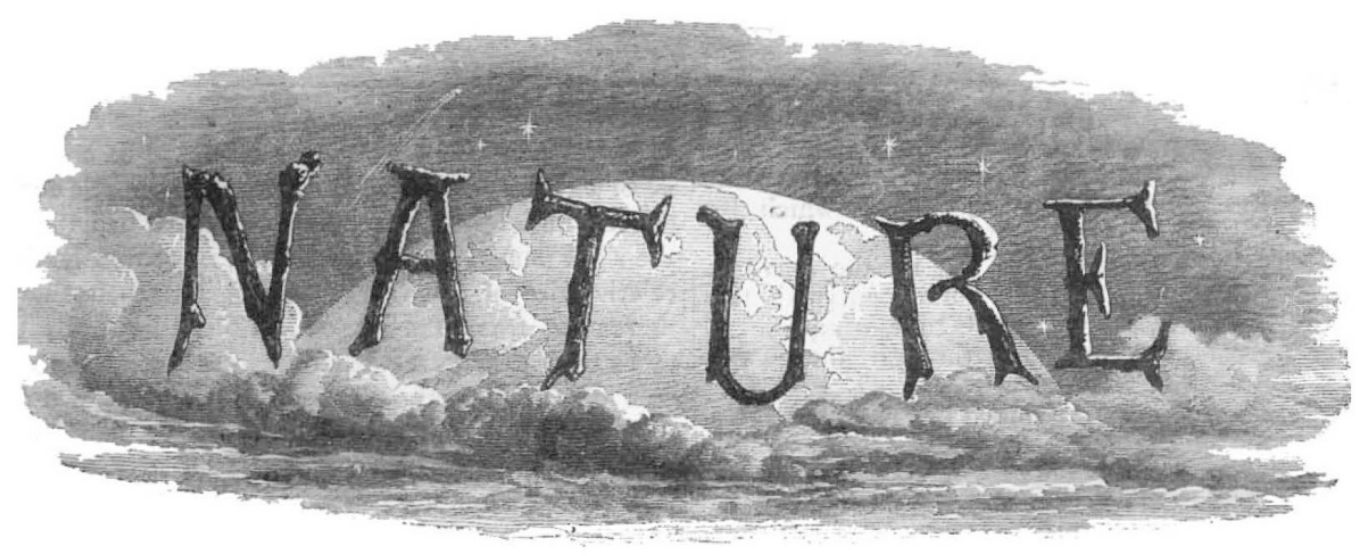

A WEEKLY ILLUSTRATED JOURNAL OF SCIENCE

"To the solid ground

of Nature trusts the mind rohich builds for aye."-WORDSWORTH

THURSDAY, NOVEMBER 6, I879

\section{ON CERTAIN ERRORS RESPECTING THE STRUCTURE OF THE HEART ATTRIBUTED TO ARISTOTLE}

$\mathrm{T}$ all the commentaries upon the "Historia Animalium" $I$ which I have met with, Aristotle's express and repeated statement, that the heart of man and the largest animals contains only three cavities, is noted as a remarkable error. Even Cuvier, who had a great advantage over most of the commentators in his familiarity with the subject of Aristotle's description, and whose habitual caution and moderation seem to desert him when the opportunity of panegyrising the philosopher presents itself, is betrayed into something like a sneer on this topic.

"Du reste il n'attribue à cet organe que trois cavités, erreur qui prouve au moins qu'il en avait regardé la structure." 1

To which remark, what follows will, I think, justify the reply, that it "prouve au moins" that Cuvier had not given ordinary attention, to say nothing of the careful study which they deserve, to sundry passages in the first and the third books of the "Historia" which I proceed to lay before the reader.

For convenience of reference these passages are marked $a, b, c, \& c^{2}$

Book i. 17.-(a) "The heart has three cavities, it lies above the lung on the division of the windpipe, and has a fatty and thick membrane where it is united with the great vein and the aorta. It lies upon the aorta, with its point down the chest, in all animals that have a chest. In all, alike in those that have a chest and in those that have none, the foremost part of it is the apex. This is often overlooked through the turning upside down of the dissection. The rounded end of the heart is uppermost, the pointed end of it is Jargely fleshy and thick, and in its cavities there are tendons. In other animals which have a chest the heart lies in the middle of the chest ; in men, more to the left side, between the nipples,

x "Histoire des Sciences Naturelles," i. p. I52. $^{2}$

a The text I have followed is that given by Aubert and Wimmer, "Aristoteles Thierkunde ; kritsich berichtigter Text mit deutschen Uebersetzung;" but $I$ have tried here and there to bring the English version rather closer to the original than the German translation, excellent as it is, seems to me to be.

VoL. XxI. - No. 523 a little inclined to the left nipple in the upper part of the chest. The heart is not large, and its general form is not elongated but rounded, except that the apex is produced into a point.

(b) "It has, as already stated, three cavities, the largest of them is on the right, the smallest on the left, the middle-sized one in the middle; they have all, also the two small ones, passages ( $\tau \epsilon \tau p \eta \mu^{\prime}$ v $^{\prime}$ ) towards the lung, very evidently as respects one of the cavities. In the region of the union [with the great vein and the aorta] the largest cavity is connected with the largest vein (near which is the mesentery); the middle cavity, with the aorta.

(c) "Canals ( $\left.\pi \delta^{\prime} \rho \circ\right)$ from the heart pass to the lung and divide in the same fashion as the windpipe does, closely accompanying those from the windpipe through the whole lung. The canals from the heart are uppermost.

(d) "No canal is common [to the branches of the wind-

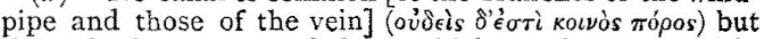
through those parts of them which are in contact $(\tau \dot{\eta} \nu$

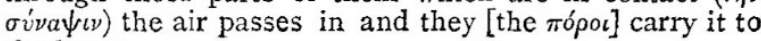
the heart.

(e) "One of the canals leads to the right cavity, the other to the left.

$(f)$ "Of all the viscera, the heart alone contains blood [in itself]. The lung contains blood, not in itself but in the veins, the heart in itself; for in each of the cavities there is blood ; the thinnest is in the middle cavity."

(Book iii. 3).-- $(g)$ " Two veins lie in the thorax alongside the spine, on its inner face; the larger more forwards, the smaller behind; the larger more to the right, the smaller, which some call aorta (on account of the tendinous part of it seen in dead bodies), to the left. These take their origin from the heart; they pass entire, preserving the nature of veins, through the other viscera that they reach ; while the heart is rather a part of them, and more especially of the anterior and larger one, which is continued into veins above and below, while between these is the heart.

(h) "All hearts contain cavities, but in those of very small animals the largest (cavity) is hardly visible, those of middling size have another, and the biggest all three.

(i) "The point of the heart is directed forwards as was mentioned at first; the largest cavity to the right and upper side of it, the smallest to the left, and the middle sized one between these; both of these are much smaller than the largest.

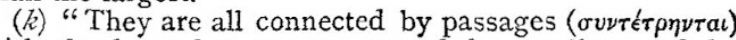
with the lung, but on account of the smallness of the canals this is obscure except in one. 
(l) "The great vein proceeds from the largest cavity which lies upwards and to the right; next through the hollow middle ( $\delta \dot{a}$ rov koì again, this cavity being a part of the vein in which the blood stagnates.

(m) "The aorta [proceeds from] the middle [cavity], but not in the same way, for it is connected [with the

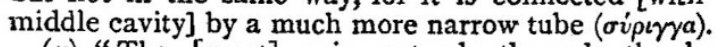

(n) "The [great] vein extends through the heart, towards the aorta from the heart.

(o) "The great vein is membranous like skin, the aorta narrower than it and very tendinous, and as it extends towards the head and the lower parts it becomes narrow and altogether tendinous.

$(p)$ "In the first place, a part of the great vein extends upwards from the heart towards the lung and the attachment of the aorta, the vein being large and undivided. It divides into two parts, the one to the lung, the other to the spine and the lowest vertebra of the neck.

(q) "The vein which extends to the lung first divides into two parts for the two balves of it and then extends alongside each tube ( $\sigma \dot{v} \rho \imath \gamma \gamma a)$ and each passage $(\tau \rho \hat{\eta} \mu a)$, the larger beside the larger and the smaller beside the smaller, so that no part [of the lung] can be found from which a passage $(\tau \rho \hat{\eta} \mu a)$ and a vein are absent. The terminations are invisible on account of their minuteness, but the whole lung appears full of blood. The canals from the vein lie above the tubes given off from the windpipe.",

The key to the whole of the foregoing description of the heart lies in the passages $(g)$ and $(l)$. They prove that Aristotle, like Galen, five hundred years afterwards, and like the great majority of the old Greek anatomists, did not reckon what we call the right auricle as a constituent of the heart at all, but as a hollow part or cilatation of the "great vein." Aristotle is careful to state that his observations were conducted on suffocated animals; and if any one will lay open the thorax of a $\mathrm{dog}$ or a rabbit, which has been killed with chloroform, in such a manner as to avoid wounding any important vessel, he will at once see why Aristotle adopted this view.

For, the vena cava inferior $(b)$, the right auricle $(R . \alpha)$ and the vena cava superior and innominate vein (V.I.) distended with blood, seem to form one continuous column, to which the heart is attached as a sort of appendage $(g)$. This column is, as Aristotlesays, vein above $(a)$ and vein below $(b)$, the upper and the lower divisions

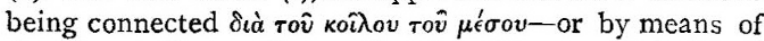
the intervening cavity or chamber $(R, a$.)-which is the right auricle.

But when, from the four cavities of the heart recognised by us moderns, one is excluded, there remain threewhich is just what Aristotle says. The solution of the difficulty is, in fact, as absurdly simple as that presented by the egg of Columbus ; and any error there may be, is not to be put down to Aristotle, but to that inability to comprehend that the same facts may be accurately described in different ways, which is the special characteristic of the commentatorial mind. That the three cavities mentioned by Aristotle are just those which remain if the right auricle is omitted, is plain enough from what is said in $(b),(c),(e),(i)$, and $(l)$. For, in a suffocated animal, the "right cavity" which is directly connected with the great vein and is obviously the right ventricle, being distended with blood, will look much Jarger than the middle cavity, which, since it gives rise to the aorta, can only be the left ventricle. And this, again, will appear larger than the thin and collapsed left auricle, which must be Aristotle's left cavity, inasmuch as this cavity is said to be connected by

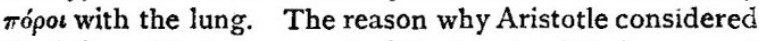
the left auricle to be a part of the heart, while he merged the right auricle in the great vein, is, obviously, the small relative size of the venous trunks and their sharper demarcation from the auricle. Galen, however, perhaps more consistently, regarded the left auricle also as a mere part of the "arteria venosa." The canal which leads from the right cavity of the heart to the lung is, without doubt, the pulmonary artery. But it may be said that, in this case, Aristotle contradicts himself, inasmuch as in $(p)$ and $(q)$ a vessel which is obviously the pulmonary artery, is described as a branch of the great vein. How-

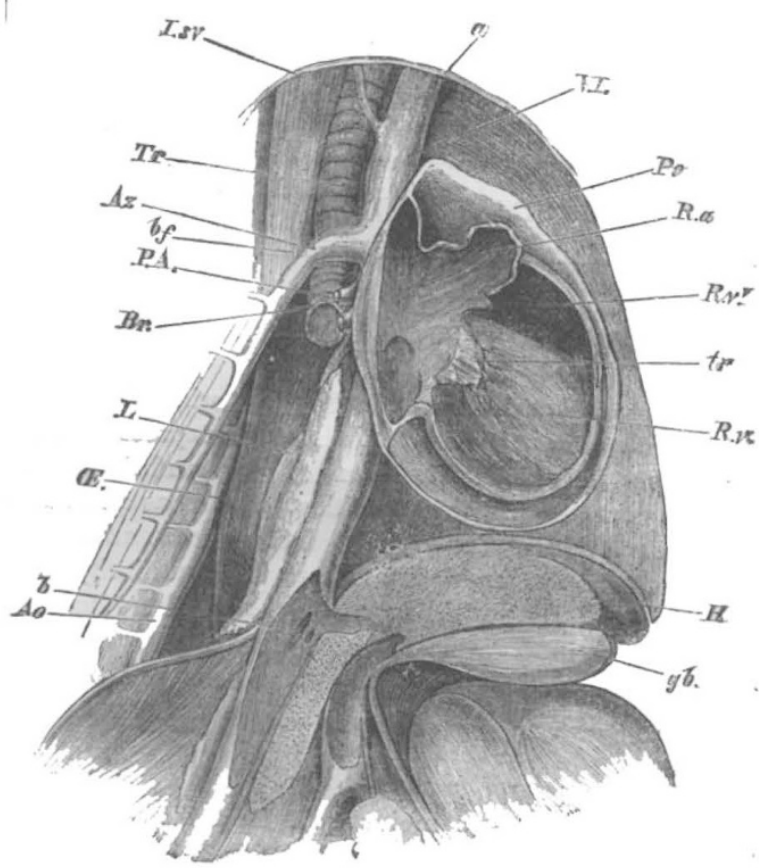

F1G. r.-A dog having been killed by chloroform, enough of the right wall of the thorax was removed, without any notable bleeding, to expose the thoracic viscera. A cacefully measured outline sketch of the parts in situ was then made, and on dissection, twenty-four hours afterwards, the necessary anatomical details were added. The woodcut is a faithfully reduced copy of the drawing thus constructed; and it represents the relations of the heart and great vessels as Aristotle saw them in a suffocated animal.

All but the inner lobe of the right lung has been removed; as well as the right half of the pericardium and the right walls of the right auricle and
ventricle. It must be remembered that the thin transparent pericardial membrane appears nothing like so distinct in nature.

a.b., Aristotle's "great vein "; V.I., right vena innominata and vena cava superior; $b$, the inferior vena cava $; R . a$, the " hollow middle" part of the great vein or the right auricle; $R \cdot v^{\prime}$, the prolongation of the cavity of the right ventricle $R . \eta$ towards the pulmonary artery; tr, one of the tricuspid valves; $P c$, the pericardium; $I . s v$, superior intercortal vein ; $A z$, vena azygos; $P$. A., right pulmonary artery; $B r$, right bronchus ; $L$, posterior lobe of the right lung; $C E$, œsophagus; $A o$, descending aorta; $H$, liver, in section, with hepatic vein, vena portæ, and gallbladder, $g b$, separated by the diaphragm, als seen ill section, from the
thoracic cavity.

ever, this difficulty also disappears, if we reflect that, in Aristotle's way of looking at the matter, the line of demarcation between the great vein and the heart coincides with the right auriculo-ventricular aperture ; and that, inasmuch as the conical prolongation of the right ventricle which leads to the pulmonary artery (Fig. I, R. $v^{\prime}$ ), lies close in front of the auricle, its bise may very easily (as the figure shows) be regarded as part of the general opening of the great vein into the right ventricle. In fact 
it is clear that Aristotle, having failed to notice the valves of the heart, did not distinguish the part of the right ventricle from which the pulmonary artery arises $\left(R . v^{\prime}\right)$ from the proper trunk of the artery on the one hand, and from the right auricle $(R . a)$ on the other. Thus the root, as we may call it, of the pulmonary artery and the right auricle, taken together, are spoken of as the "part of the great vein which extends upwards ;" and, as the vena azygos $(A z)$ was one branch of this, so the "vein to the lung" was another branch of it. But the latter branch, being given off close to the connection of the great vein with the ventricle, was also counted as one of the two mópor by which the "heart" (that is to say the right ventricle, the left ventricle, and the left auricle of our nomenclature) communicates with the lung.

The only other difficulty that I observe, is connected with $(k)$. If Aristotle intended by this to affirm that the middle cavity (left ventricle), like the other two, is directly connected with the lung by a $\pi$ ópos, he would be in error. But he has excluded this interpretation of his words by $(e)$, in which the number and relations of the canals, the existence of which he admits, are distinctly defined. I can only imagine then, that so far as this passage applies to the left ventricle, it merely refers to the indirect communication of that cavity with the vessels of the lungs, through the left auricle.

On this evidence I submit that there is no escape from the conclusion that, instead of having committed a gross blunder, Aristotle has given a description of the heart which so far as it goes, is remarkably accurate. He is in error only in regard to the differences which he imagines to exist between large and small hearts $(h)$.

Cuvier (who has been followed by other commentators) ascribes another error to Aristotle :-

"Aristote suppose que la trachée-artère se prolonge jusqu'au cour, et semble croire, en conséquence, que l'air y pénétre (l. c. p. 152)."

Upon what foundation Cuvier rested the first of these two assertions, I am at a loss to divine. As a matter of fact, it will appear from the following excerpts that Aristotle gives an account of the structure of the lungs which is almost as good as that of the heart, and that it contains nothing about any prolongation of the windpipe to the heart.

"Within the neck lie what is called the oesophagus (so named on account of its length and its narrowness) and the windpipe (áprnpia). The position of the windpipe in all animals that have one, is in front of the œsophagus. All animals which possess a lung have a windpipe. The windpipe is of a cartilaginous nature and is exsanguine, but is surrounded by many little veins . . . .

"It goes downwards towards the middle of the lung and then divides for each of the halves of the lung. In all animals that possess one, the lung is divided into two parts; but, in those which bring forth their young alive, the separation is not equally well marked, least of all in man.

"In oviparous animals, such as birds, and in quadrupeds which are oviparous, the one half of the lung is widely separated from the other ; so that it appears as if they had two lungs. And from being single the windpipe becomes [divided into] two, which extend to each half of the lung. It is fastened to the great vein and to what is called the aorta. When the windpipe is blown up the air passes into the hollow parts of the lung. In these, are

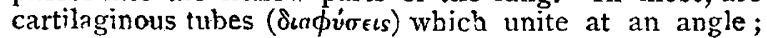

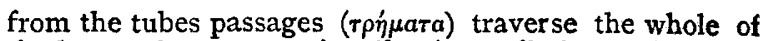
the lung ; they are continually given off, the smaller from the larger." (Book i., I6.)

That Aristotle speaks of the lung as a single organ divided into two halves and says that the division is least marked in man, is puzzling at first, but becomes intelligible if we reflect upon the close union of the bronchi, the pulmonary vessels and the mediastinal walls of the pleuræ in mammals; ${ }^{1}$ and it is quite true that the lungs are much more obviously distinct from one another in birds.

Aubert and Wimmer translate the last paragraph of the passage just cited as follows :-

"Diese haben aber knorpelige Scheidewände, welche unter spitzen Winkeln zusammentreten, und aus ihnen führen Oeffnungen durch die ganze Lunge, indem sie sich in immer kleineren verzweigen."

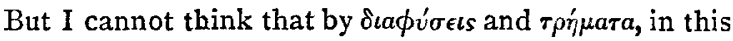
passage, Aristotle meant either "partitions" or openings in the ordinary sense of the latter word. For, in Book iii., Cap. 3, in describing the distribution of the "vein which goes to the lung" (the pulmonary artery), he says that it

"Extends alongside each tube ( $\sigma^{\prime} v^{\prime}(\gamma \gamma \alpha)$ and each passage $(\tau p \hat{\eta} \mu a)$, the larger beside the larger, and the smaller beside the smaller; so that no part [of the lung] can be found from which a passage $(\tau \rho \hat{\eta} \mu a)$ and a vein are absent."

Moreover, in Book i., 17, he says-

"Canals ( $\pi$ ópoc) from the heart pass to the lung and divide in the same fashion as the windpipe does, closely accompanying those from the windpipe through the whole lung."

And again in Book i., 17.-

"It (the lung) is entirely spongy, and alongside of each

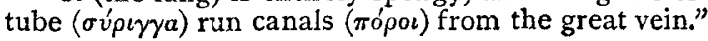

On comparing the last three statements with the facts of the case, it is plain that by $\sigma u ́ p$ means the bronchi and so many of their larger divisions as obviously contain cartilages; and that by $\delta \iota \alpha \phi v \sigma \epsilon t s$ $\chi \circ \nu \delta \rho \omega \delta \epsilon u s$ he denotes the same things; and, if this be so, then the $\tau \rho$ '́nara must be the smaller bronchial canals, in which the cartilages disappear.

This view of the structure of the lung is perfectly correct so far as it extends; and, bearing it in mind, we shall be in a position to understand what Aristotle thought about the passage of air from the lungs into the heart. In every part of the lung, he says, in effect, there is an air tube which is derived from the trachea, and other tubes which are derived from the rópoe which lead from the lung to the heart, suprà $(c)$. Their applied walls constitute the thin "synapses" ( $\tau \dot{\eta} \nu \sigma v \dot{\nu} \psi(\nu)$ through which the air passes out of the air tubes into the trópol, or blood vessels, by transudation or diffusion; for there is no community between the cavities of the air tubes and cavities of the canals ; that is to say, no opening from one into the other, supra $(d)$.

On the words "koı̀òs nópos" Aubert and Wimmer remark (l.c. p. 239), " $\mathrm{Da}$ A. die Ansicht hat die Lungenluft würde dem Herzen zugeführt, so postulirt er statt vieler kleiner Verbindungen einen grossen Verbindungsgang zwischen Lunge und Herz."

But does Aristotle make this assumption? The only evidence so far as I know in favour of the affirmative answer to this question is the following passage :-

* In modern works on Veterinary Anatomy the 'irgs are ssmetime described as two lobes of a single organ. 


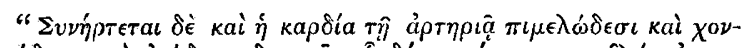

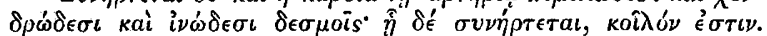

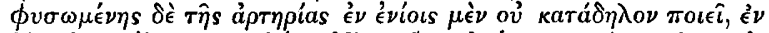

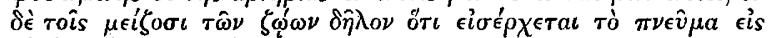
av่rท́ " (i. cap. 16).

"The heart and the windpipe are connected by fatty and cartilaginous and fibrous bands ; where they are connected it is hollow. Blowing into the windpipe does not show clearly in some animals, but in the larger animals it is clear that the air goes into it."

Aubert and Wimmer give a somewhat different rendering of this passage :-

"Auch das Herz hängt mit der Luftröhre durch fettreiche, knorpelige und faserige Bänder zusammen; und da, wo sie zusammenhängen, ist eine Höhlung. Beim Autblasen der Lunge wird es bei manchen Thieren nicht wahrnehmbar, bei den grösseren aber ist es offenbar, dass die Luft in das Herz gelangt."

The sense here turns upon the signification which is to be ascribed to eis aiviny. But if these words refer to the heart, then Aristotle has distinctly pointed out the road which the air, in his opinion, takes, namely, through the "synapses"; and there is no reason that I can discover to believe that he "postulated" any other and more direct communication.

With respect to the meaning of koì $\hat{o}^{\nu} \dot{\epsilon} \sigma \tau \iota \nu$, Aubert and Wimmer observe :-

"Dies scheint wohl die kurze Lungenvene zu sein. Schneider bezieht dies auf die Vorkammern, allein diese werden unten als Höhlen des Herzens beschrieben."

I am disposed to think, on the contrary, that the words refer simply to the cavity of the pericardium. For a part of this cavity (sinus transversus pericardii) lies between the aorta, on the one hand, and the pulmonary vessels with the bifurcation of the trachea, on the other hand, and is much more conspicuous in some animals than in man. It is strictly correct, therefore, in Aristotle's words, to say that where the heart and the windpipe are connected "it is hollow." If he had meant to speak of one of the pulmonary veins, or of any of the cavities of the heart, he would have used the terms $\pi$ ópo or koi iias which he always employs for these parts.

According to Aristotle, then, the air taken into the lungs passes from the final ramifications of the bronchial tubes into the corresponding branches of the pulmonary blood vessels, not through openings, but by transudation, or, as we should nowadays say, diffusion, through the thin partitions formed by the applied coats of the two sets of canals. But the "pneuma" which thus reached the interior of the blood vessels was not, in Aristotle's opinion, exactly the same thing as the air. It was "áp $\pi 0 \lambda$ 's

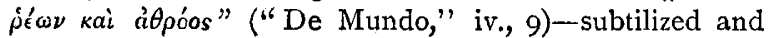
condensed air; and it is hard to make out whether Aristotle considered it to possess the physical properties of a gas or those of a liquid. As he affirms that all the cavities of the heart contain blood $(f)$, it is clear that he dia not hold the erroneous view propounded in the next generation by Erasistratus. On the other hand, the fact that he supposes that the spermatic arteries do not contain

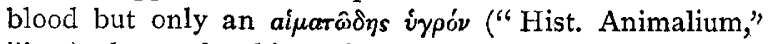
iii., I), shows that his notions respecting the contents of the arteries were vague. Nor does he seem to have known that the pulse is characteristic only of the arteries; and as he thought that the arteries end in solid fibrous bands, he naturally could not have entertained the faintest conception of the true motion of the blood. But without attempting to read into Aristotle modern conceptions which never entered his mind, it is only just to observe that his view of what becomes of the air taken into the lungs is by no means worthy of contempt as a gross error. On the contrary, here, as in the case of his anatomy, what Aristotle asserts is true as far as it goes. Something does actually pass from the air contained in the lungs through the coats of the vessels into the blood, and thence to the heart; to wit, oxygen. And I think that it speaks very well for ancient Greek science that the investigator of so difficult a physiological problem as that of respiration, should have arrived at a conclusion, the statement of which, after the lapse of more than two thousand years, can be accepted as a thoroughly established scientific truth.

I trust that the case in favour of removing the statements about the heart, from the list of the "errors of Aristotle" is now clear; and that the evidence proves, on the contrary, that they justify us in forming a very favourable estimate of the oldest anatomical investigations among the Greeks of which any sufficient record remains.

But is Aristotle to be credited with the merit of having ascertained so much of the truth? This question will not appear superfluous to those who are acquainted with the extraordinary history of Aristotle's works, or who adopt the conclusion of Aubert and Wimmer, that, of the ten books of the "Historia Animalium" which have come down to us, three are largely or entirely spurious and that the others contain many interpolations by later writers.

It so happens, however, that, apart from other reasons, there are satisfactory internal grounds for ascribing the account of the heart to a writer of the time at which Aristotle lived. For, within thirty years of his death, the anatomists of the Alexandrian school had thoroughly investigated the structure and the functions of the valves of the heart. During this time, the manuscripts of Aristotle were in the possession of Theophrastus; and no interpolator of later date would have shown that he was ignorant of the nature and significance of these important structures, by the brief and obscure allusion-"in its cavities there are tendons (a)." On the other hand, Polybus, whose account of the vascular system is quoted in the "Historia Animalium" was an elder contemporary of Aristotle. Hence, if any part of the work faithfully represents that which Aristotle taught, we may safely conclude that the description of the heart does so. Having granted this much, however, it is another question, whether Aristotle is to be regarded as the first discoverer of the facts which he has so well stated, or whether he, like other men, was the intellectual child of his time and simply carried on a step or two the work which had been commenced by others.

On the subject of Aristotle's significance as an original worker in biology extraordinarily divergent views have been put forward. If we are to adopt Cuvier's estimate, Aristotle was simply a miracle :-

"Avant Aristote la philosophie, entièrement spéculative, se perdait dans les abstractions dépourvues de fondement ; la science n'existait pas. Il semble qu'elle soit sortie toute faite du cerveau d'Aristote comme Minerve, toute armée, du cerveau de Jupiter. Seul, en effet, sans antécédents, sans rien emprunter aux siècles qui l'avaient pré. 
cédé, puisqu'ils n'avaient rien produit de solide, le disciple de Platon découvrit et démontra plus de vérités, executa plus de travaux scientifiques en un vie de soixante-deux ans, qu'après lui vingt siècles n'en ont pu faire," 1 \&c., \&c.

"Aristote est le premier qui ait introduit la méthode de l'induction, de la comparaison des observations pour en faire sortir des idées générales, et celle de l'expérience pour multiplier les faits dont ces idées générales peuvent être déduites."-ii. p. 515.

The late Mr. G. H. I.ewes, ${ }^{2}$ on the contrary, tells us " on a superficial examination, therefore, he [Aristotle] will seem to have given tolerable descriptions ; especially if approached with that disposition to discover marvels which unconsciously determines us in our study of eminent writers. But a more unbiased and impartial criticism will disclose that he has given no single anatomical description of the least value. All that he knew may have been known and probably was known, without dissection. .... I do not assert that he never opened an animal; on the contrary, it seems highly probable that he had opened many ...... He never followed the course of a vessel or a nerve; never laid bare the origin and insertion of a muscle; never discriminated the component parts of organs; never made clear to himself the connection of organs into systems." -(pp. 1 56-7.)

In the face of the description of the heart and lungs, just quoted, I think we may venture to say that no one who has acquired even an elementary practical acquaintance with anatomy, and knows of his own knowledge that which Aristotle describes, will agree with the opinion expressed by Mr. Lewes; and those who turn to the accounts of the structure of the rock lobster and that of the lobster, or to that of the Cephalopods and other Mollusks, in the fourth book of the "Historia Animalium" wiil probably feel inclined to object to it still more strongly.

Gn the other hand, Cuvier's exaggerated panegyric will as little bear the test of cool discussion. In Greece, the century before Aristotle's birth was a period of great in tellectual activity, in the field of physical science no less than elsewhere. The method of induction has never been used to better effect than by Hippocrates; and the labours of such men as Alkmeon, Demokritus, and Polybus among Aristotle's predecessors, Diokles, and Praxagoras, among his contemporaries, laid a solid foundation for the scientific study of anatomy and development, independently of his labours. Aristotle himself informs us that the dissection of animals was commonly practised ; that the aorta had been distinguished from the great vein; and that the connection of both with the heart had been observed by his predecessors. What they thought about the structure of the heart itself, or that of the lungs, he does not tell us, and we have no means of knowing. So far from arrogantly suggesting that he owed nothing to his predecessors, Aristotle is careful to refer to their observations and to explain why, in his judgment, they fell into the errors which he corrects.

Aristotle's knowledge, in fact, appears to have stood in the same relation to that of such men as Polybus and Diogenes of Apollonia, as that of Herophilus and Erasistratus did to his own, so far as the heart is concerned. He carried science a step beyond the point at which he found it; a meritorious, but not a miraculous, achievement. What he did required the possession of very good powers of observation; if they had been powers of the highest class he could hardly have left such conI "Histoire des Sciences Naturelles."-t. i. p. I30. 2 "Aristotie, a Chapter from the History of Science." spicuous objects as the valves of the heart to be discovered by his successors.

And this leads me to make a final remark upon a singular feature of the "Historia Animalium." As a whole, it is a most notable production, full of accurate information and of extremely acute generalisations of the observations accumulated by naturalists up to that time. And yet, every here and there, one stumbles upon assertions respecting matters which lie within the scope of the commonest inspection, which are not so much to be called errors as stupidities. What is to be made of the statement that the sutures of women's skulls are different from those of men; that men and sundry male animals have more teeth than their respective females; that the back of the skull is empty, and so on? It is simply incredible to me that the Aristotle who wrote the account of the heart, also committed himself to absurdities which can be excused by no theoretical prepossession and which are contradicted by the plainest observation.

What, after all, were the original manuscripts of the "Historia Animalium"? If they were notes of Aristotle's lectures taken by some of his students, any lecturer who has chanced to look through such notes, would find the interspersion of a foundation of general and sometimes mintute accuracy, with patches of transcendent blundering, perfectly intelligible. Some competent Greek scholar may perhaps think it worth while to tell us what may be said for or against the hypothesis thus hinted. One obvious difficulty in the way of adopting it is the fact that, in other works, Aristotle refers to the "Historia Animalium" as if it had already been made public by himself.

T. H. HUXLEY

ON THE NECESSITY FOR A NEW

DEPARTURE IN SPECTRUM ANALYSTS

$\mathrm{T}$ is now about a year since I gave an account of the results to which the final discussion of a complete set of photographs of the spectra of the metallic elements compared with the spectrum of the sun had led me.

The comparison was limited necessarily to the blue and violet portions of the spectrum, as photography was employed, and the methods since worked out by Capt. Abney for photographing the other regions were not then available. Of set purpose I limited it still more, as I wished to find the dernier mot in the present state of science regarding the coincidence of metallic with Fraunhofer's lines; and for this it was imperative to work on a large scale over a small region rather than on a small scale over a large one.

In point of fact, the work was limited to about the $\frac{7}{100}$ th part of the spectrum, and this small part was mapped on a large scale. A complete map of the spectrum on the scale adopted would be about half a furlong long. The work took time : including interruptions of one kind and another, some four years were expended on it.

I have elsewhere discussed at some length the concfusion which stared us in the face when all the work was brought to focus, but it is important that I should here dwell upon it for a moment, especially as it is now possible, perhaps, to state it with more terseness and clearness than one could at first, when the new conception thus forced upon us and its consequences were less familiar to one's mind. 